\title{
Neuromuscular function and plasma drug levels in pyridostigmine treatment of myasthenia gravis
}

U Breyer-Pfaff, A Schmezer, U Maier, A Brinkmann, F Schumm

\begin{abstract}
In 18 patients with generalised myasthenia treated with oral pyridostigmine, muscular strength, decrement of neuromuscular transmission in the trapezius muscle on repetitive accessory nerve stimulation, and pyridostigmine plasma level were measured repeatedly during 1-3 dosing intervals. Significant correlations between pyridostigmine concentrations and functional parameters were present in three out of 11 cases in which plasma levels changed by at least $25 \mathrm{ng} / \mathrm{ml}$ during the investigational period and peak levels did not exceed $100 \mathrm{ng} / \mathrm{ml}$. Several other observations indicated that pyridostigmine at levels above $100 \mathrm{ng} / \mathrm{ml}$ may impair neuromuscular function.
\end{abstract}

In the symptomatic treatment of myasthenia gravis with the anticholinesterase drug pyridostigmine, prescribed oral doses vary over a wide range, at least from 60 to $1500 \mathrm{mg}$ / day. ${ }^{12}$ Individual optimisation is required because doses that are too high may impair muscle strength due to an excess of acetylcholine. ${ }^{3}$ In addition, the kinetics of orally administered pyridostigmine are complicated by low and variable availability. ${ }^{45}$ Dose adjustment with the aid of plasma concentrations is hampered by the lack of a commonly accepted therapeutic range of pyridostigmine concentrations. ${ }^{6}$ Its establishment would require measurement of plasma concentrations in patients in parallel to an evaluation of the clinical state. The purpose of this study was to obtain data of this kind in a larger group of patients than those investigated previously. ${ }^{17}$

\section{Patients and methods}

Patient group

The study included 11 female and seven male patients with generalised myasthenia. Six of them were investigated two or three times at intervals of two weeks to three years, so that a total of 27 investigations were carried out, but detailed functional evaluation was only possible in 26. Pharmacokinetic data from six of the patients were included in a previous publi-

Table Demographic data, pyridostigmine doses and plasma concentrations, and patients scores

University of Tübingen, Tübingen Department of Toxicology U Breyer-Pfaff A Schmezer U Maier

Department of Neurology A Brinkmann

Clinic of Neurology Christophsbad, Göppingen, Federal Republic of Germany F Schumm

Correspondence to: Dr Ursula Breyer-Pfaff, Institut für Toxikologie, Universitat Tubingen, Wilhelmstrasse 56, D-7400 Tübingen, Federal Republic of Germany.

Received 29 November 1988 and in final revised form and in final revised Accepted 4 October 1989

\begin{tabular}{|c|c|c|c|c|c|c|c|c|}
\hline \multirow[b]{2}{*}{ Cases ${ }^{\star}$} & \multirow[b]{2}{*}{ Sex } & \multirow[b]{2}{*}{$\begin{array}{l}\text { Age } \\
(y r)\end{array}$} & \multicolumn{5}{|c|}{ Pyridostigmine $\dagger$} & \multirow[b]{2}{*}{ Mean score } \\
\hline & & & $\begin{array}{l}\text { Daily } \\
\text { dose (mg) }\end{array}$ & $\begin{array}{l}\text { Single } \\
\text { dose (mg) }\end{array}$ & $\begin{array}{l}C \\
(n g / m l)\end{array}$ & $\begin{array}{l}C \max \\
(\mathbf{m g} / m l)\end{array}$ & $\begin{array}{l}A U C \\
(n g . \min / \mathrm{ml})\end{array}$ & \\
\hline \multicolumn{9}{|c|}{ Group A } \\
\hline $\begin{array}{c}1 / a \\
c\end{array}$ & $\mathrm{~m}$ & $\begin{array}{l}38 \\
39\end{array}$ & 240 & 60 & 22 & 23 & 4800 & $1 \cdot 8$ \\
\hline $2^{i c}$ & $\mathrm{~m}$ & $\begin{array}{l}39 \\
75\end{array}$ & $\begin{array}{l}330 \\
160\end{array}$ & $\begin{array}{l}60 \\
40\end{array}$ & $\begin{array}{l}28 \\
51\end{array}$ & $\begin{array}{l}29 \\
58\end{array}$ & $\begin{array}{r}6600 \\
15100\end{array}$ & $\begin{array}{l}2 \cdot 6 \\
3 \cdot 1\end{array}$ \\
\hline $3 / a$ & $\mathrm{f}$ & 22 & 240 & 60 & 29 & 44 & $\begin{array}{r}13100 \\
6600\end{array}$ & $\begin{array}{l}2.1 \\
1.5\end{array}$ \\
\hline b & & 22 & 300 & 60 & 45 & 57 & 9900 & $3 \cdot 2$ \\
\hline 4 & f & 31 & 300 & 60 & 30 & 38 & 7200 & 1.5 \\
\hline 5 & f & 41 & 200 & 50 & 33 & 37 & 8000 & $2 \cdot 2$ \\
\hline 6 & f & 41 & 370 & 60 & 68 & 72 & 14200 & 0.8 \\
\hline 7 & f & 61 & 90 & 30 & 21 & 25 & 5150 & 1.8 \\
\hline $8 / a$ & f & 64 & 160 & 40 & 21 & 35 & 5600 & 0.9 \\
\hline \multicolumn{9}{|c|}{ Group B } \\
\hline $1 / \mathrm{b}$ & $\mathrm{m}$ & 38 & 330 & 60 & 39 & 69 & 10500 & $3 \cdot 3$ \\
\hline $9 / \mathrm{b}$ & $\mathrm{m}$ & 43 & 200 & 50 & 49 & 66 & 15000 & 0.6 \\
\hline c & & 46 & 330 & 60 & 62 & 85 & 14200 & 1.8 \\
\hline $10 / \mathrm{c}$ & $\mathrm{m}$ & 54 & 270 & 60 & 53 & 66 & - & 1.6 \\
\hline 11 & $\mathrm{~m}$ & 54 & 240 & 60 & 43 & 69 & 12300 & 0.4 \\
\hline 12 & $\mathrm{~m}$ & 55 & 300 & 60 & 50 & 76 & 10700 & $3 \cdot 8$ \\
\hline 13 & $\mathrm{~m}$ & 63 & 120 & 40 & 59 & 70 & & 0.7 \\
\hline $14 / a$ & f & 39 & 220 & 50 & 52 & 66 & 17800 & $2 \cdot 0$ \\
\hline $8 / \mathrm{b}$ & f & 64 & 320 & 80 & 46 & 63 & 12500 & 0.9 \\
\hline 15 & f & 65 & 120 & 60 & 32 & 48 & 12000 & $2 \cdot 8$ \\
\hline 16 & $\mathrm{f}$ & 78 & 140 & 35 & 60 & 72 & 17900 & 0.9 \\
\hline \multicolumn{9}{|c|}{ Group C } \\
\hline $9 / a$ & $\mathrm{~m}$ & 43 & 240 & 60 & 89 & 117 & 31650 & $3 \cdot 3$ \\
\hline $\begin{array}{r}10 / a \\
/ b\end{array}$ & $\mathrm{~m}$ & $\begin{array}{l}53 \\
53\end{array}$ & 240 & 60 & 54 & 135 & 13800 & 1.7 \\
\hline $17^{10}$ & f & $\begin{array}{l}53 \\
21\end{array}$ & $\begin{array}{l}240 \\
160\end{array}$ & $\begin{array}{l}60 \\
40\end{array}$ & $\begin{array}{r}97 \\
109\end{array}$ & $\begin{array}{l}127 \\
152\end{array}$ & 24300 & $\begin{array}{l}2 \cdot 7 \\
2 \cdot 2\end{array}$ \\
\hline $14 / b$ & f & 39 & 280 & 60 & 117 & 197 & $\overline{40900}$ & $\mathrm{~nm} \ddagger$ \\
\hline 18 & f & 57 & 240 & 60 & 70 & 106 & 16800 & 1.5 \\
\hline
\end{tabular}


cation. ${ }^{5}$ All patients were in stage II according to Osserman ${ }^{8}$ except 3 and 14 who were in stage III of the disease. With a few exceptions they had undergone thymectomy. Demographic data and data on pyridostigmine treatment are presented in the table. Glucocorticoids were given as comedication in 15 cases, azathioprine in 12, antacids in 11 , and antisecretory drugs in seven. The routine treatment was carried on during the investigation.

\section{Study protocol}

At each time point, $10 \mathrm{ml}$ of blood was drawn into a heparinised tube, immediately centrifuged and frozen after mixing with $0.1 \mathrm{M}$ $\mathrm{NaH}_{2} \mathrm{PO}_{4}{ }^{5}$ In addition, the following functional parameters were obtained: 1) the decrement ( $\mathrm{D} 5$, in $\%$ ) of the action potential of the trapezius muscle on repetitive $5 \mathrm{~Hz}$ stimulation of the accessory nerve (normal value up to $\left.-8^{\mathrm{o}}{ }_{0}\right) ;^{9}$ 2) a score for muscle fatigue ${ }^{10}$ derived from the times for which the arms could be held at an angle of $90^{\circ}$ in standing position (normal value $6 \mathrm{~min}$ ); a leg could be lifted to an angle of $45^{\circ}$ in supine position (normal value $2 \mathrm{~min}$ ); the head could be lifted to an angle of $45^{\circ}$ in supine position (normal value $2 \mathrm{~min}$ ). Each of the tests scored up to four (most pathological value) and the average gave the total score.

Investigations started before ingestion of a pyridostigmine dose which was the first morning dose in 15 cases, the second morning dose in six cases and the afternoon dose in six cases. Further time points of investigation were scheduled at intervals of 30 minutes for the first two hours and then at intervals of one hour at least to the time when the next dose was taken. For technical and medical reasons, this schedule was not always strictly adhered to. In four cases, the study period comprised two dosing intervals and in one case, three intervals, but the investigations were spaced one to two hours apart.

Plasma samples were stored at $-75^{\circ} \mathrm{C}$ for up to four months and analysed by HPLC. ${ }^{5}$ All measurements were carried out in duplicate, the average deviation being $10 \%$.

\section{Calculations}

Areas under plasma concentration-time curves (AUC) were obtained by the trapezoidal rule, and mean plasma levels were calculated as AUC/time. Linear regression analysis was carried out for single patients between the pyridostigmine plasma levels and functional parameters provided that they exhibited relevant changes during the investigational period. A p value of 0.05 or less was taken as the limit of statistical significance.

\section{Results \\ Plasma level data}

Mean plasma pyridostigmine concentrations during the period of investigation (1-3 dosing intervals) and AUC values varied widely among patients (table) and did not correlate significantly with the daily dose $(r=0 \cdot 16)$.

An influence of a comedication with gluco- corticoids was not apparent. When data were divided according to mean plasma concentration/daily dose ratios, patients received additional glucocorticoid treatment in seven out of 13 investigations that gave ratios above the median and in eight out of 13 with ratios below the median, respectively. Moreover, two patients were studied on drug regimes including and not including glucocorticoids: the plasma concentration/daily dose ratio increased with addition of prednisolone in one of the patients and fell in the other. Plasma concentration/dose ratios did not differ either between patients receiving and not receiving azathioprine, antacids, or antisecretory drugs.

Before ingestion of the first morning dose, pyridostigmine was always measurable in plasma at concentrations between 14 and $92 \mathrm{ng} / \mathrm{ml}$ (mean (SD) 35 (19) $\mathrm{ng} / \mathrm{ml}$ ). Neither the average nor the minimum concentrations correlated with daily doses. The time course of plasma concentrations following ingestion of a dose was highly variable between, as well as within, subjects and did not depend on whether the first morning dose or a later dose had been administered. Peak levels of $23-197 \mathrm{ng} / \mathrm{ml}$ [mean (SD) $74(41) \mathrm{ng} / \mathrm{ml}$ ] were attained 0.5$4 \mathrm{hr}$ [mean (SD) $1.8(1.0)$ hour] after dosage; they exceeded predose levels by $3-118 \mathrm{ng} / \mathrm{ml}$ [mean (SD) $38(34) \mathrm{ng} / \mathrm{ml}$ ] after a $60 \mathrm{mg}$ dose $(\mathrm{N}=17$ ) and by $2-55 \mathrm{ng} / \mathrm{ml}$ [mean (SD) 28 (19) $\mathrm{ng} / \mathrm{ml}]$ after a 40 or $50 \mathrm{mg}$ dose $(\mathrm{N}=7)$. The relative increase in the total group amounted to $6-700 \%$ [mean (SD) $110(130) \%$ ].

\section{Parameters reflecting neuromuscular function}

Total score data were available from all patients and from all investigations but one and individual means varied between 0.4 and 3.8 [mean (SD) $1.9(1.0)$ ]. Clinically relevant changes of 0.5 or more were observed in 15 cases during the investigational period, the maximum change being $1 \cdot 5$. Changes of at least 0.5 occurred in six cases in which plasma levels fluctuated by less than $25 \mathrm{ng} / \mathrm{ml}$.

Separate measures for the time that the head could be lifted (head lifting time, HLT) were documented in 17 cases, and in 11 of them there was a change of $20 \mathrm{~s}$ or more (maximal change $90 \mathrm{~s}$ ) during the period of investigation or of $10 \mathrm{~s}$ or more, respectively, in those cases in which the minimal time was less than $15 \mathrm{~s}$. In five instances HLT changed in the absence of distinct plasma concentration changes.

A pathological decrement of the trapezius muscle action potential was measured in 12 investigations in seven patients. Other patients either did not show an impairment of neuromuscular transmission or their clinical state did not allow them to carry out the measurement (three cases). The decrement that attained maximal values of -10 to $-57 \%$ in the total group changed by at least $10 \%$ (maximum change $30 \%$ ) in 10 cases.

\section{Relationships between plasma concentrations and} functional parameters

Because of the large differences between patients in their clinical state, no attempts were made to correlate plasma concentration and 
functional data in the group. Instead, data were checked for the existence of correlations within patients that would give a clue to therapeutically favourable plasma concentrations.

If the clinical state is expected to improve on raising the pyridostigmine plasma concentration, negative correlations should exist between the latter and the total score as well as the absolute value of the decrement. On the other hand, the HLT should correlate positively with plasma pyridostigmine.

Since no correlations could be expected in the absence of marked plasma concentration fluctuations, those investigations in which changes were below $25 \mathrm{ng} / \mathrm{ml}$ were placed in a separate group $(\mathrm{A}, \mathrm{N}=10)$; mean levels were below $50 \mathrm{ng} / \mathrm{ml}$ in eight of these cases and below $70 \mathrm{ng} / \mathrm{ml}$ in all of them. Moreover, for concentrations that were too high no further improvement can be expected to parallel an increase in the plasma level. Thus, a limit was tentatively set at $100 \mathrm{ng} / \mathrm{ml}$ and cases with higher peak concentrations combined as group $C(N=6)$. Group $B(N=11)$ comprised investigations in which plasma concentrations changed by $25 \mathrm{ng} / \mathrm{ml}$ or more, but did not exceed $100 \mathrm{ng} / \mathrm{ml}$ (table).

Statistically significant correlations between plasma concentrations and HLT were present in three cases $(9 / \mathrm{c}, 12,15)$, all of them belonging to group $B$. In cases $9 / c$ and 15 , significant correlations were also revealed with the total score and the decrement, respectively (fig 1). No significant correlations were found in groups $\mathrm{A}$ and $\mathrm{C}$, but in case $10 / \mathrm{a}$ a significant negative correlation between the decrement and the pyridostigmine level $(\mathrm{r}=-0.71, \mathrm{~N}$ $=8$ ) emerges on omission of the only time point with a plasma concentration above 100 $\mathrm{ng} / \mathrm{ml}$. Actually, all functional parameters
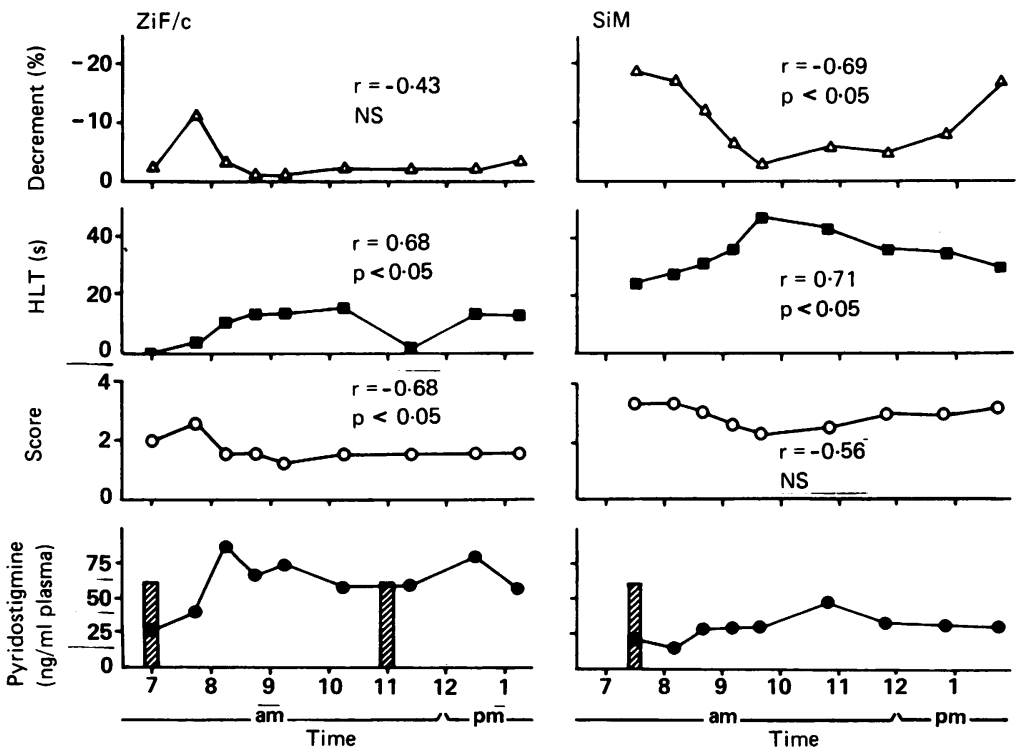

Figure 1 Time course of pyridostigmine plasma concentrations and of parameters reflecting neuromuscular function in the investigations of $9 / c$ and 15. Correlation coefficients refer to correlations with plasma levels. The hatched bars indicate ingestion of a $60 \mathrm{mg}$ dose of pyridostigmine.
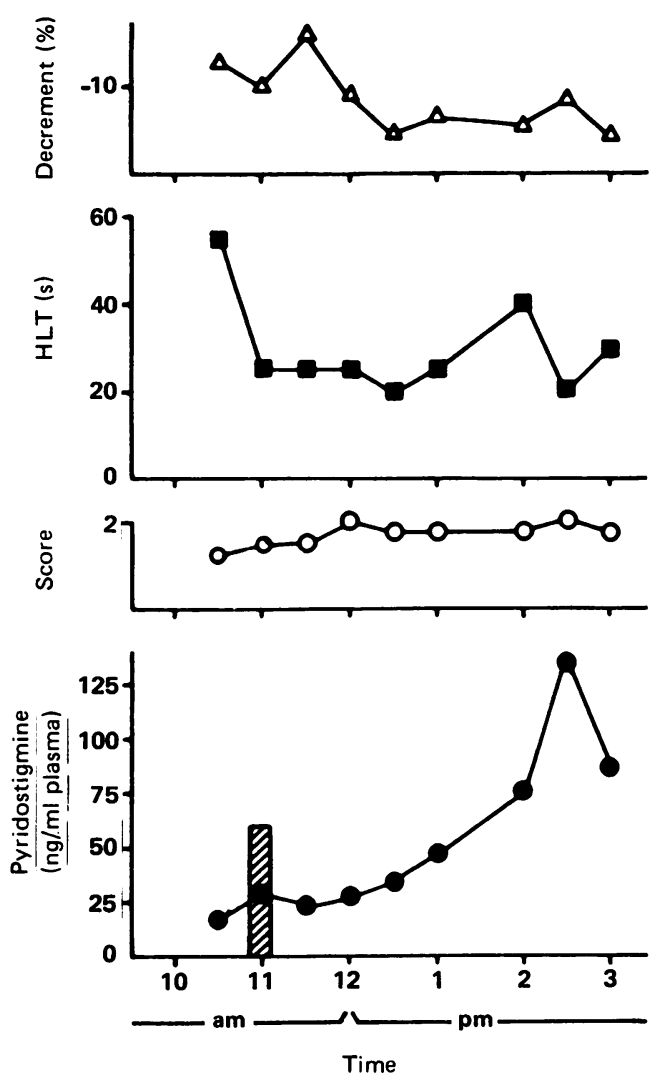

Figure 2 Time course of pyridostigmine plasma concentration and of parameters reflecting neuromuscular function in the investigation of 10/a.

The hatched bar indicates ingestion of a $60 \mathrm{mg}$ dose of pyridostigmine. Note the deterioration in all parameters at the time of the peak concentration.

deteriorated at this time relative to the preceding and the following time points (fig 2).

Even in the cases with significant correlations, there was no complete agreement between time courses of plasma concentrations and functional data. For instance, in patient 15, maximal improvement of all parameters preceded the peak pyridostigmine concentration by one hour, whereas the reverse applied in case $9 / \mathrm{c}$ (fig 1).

A further indication of the unfavourable effect of high plasma pyridostigmine concentrations is the fact that patients 9 and 10 exhibited higher scores in the investigations where maximal levels exceeded $100 \mathrm{ng} / \mathrm{ml}$ than in those comprised in group B (table). Moreover, the highest peak and mean pyridostigmine levels were observed in $14 / \mathrm{b}$. At that time, no systematic investigation was possible due to the patient's poor clinical state. She had marked muscular weakness (HLT $<10 \mathrm{sec}$ ) and cholinergic overstimulation was apparent from sialorrhoea, bronchial hypersecretion and diarrhoea. Two weeks earlier, the same patient while receiving a somewhat lower pyridostigmine dose had had plasma concentrations in the intermediate range and had been in a much better condition (14/a in group B).

\section{Discussion}

Our investigations revealed interindividual variations of mean pyridostigmine plasma con- 
centrations relative to daily dose by a factor of about five, which agrees with findings by previous investigators. ${ }^{2411-13}$ Major reasons for this can be assumed to be variabilities in the fraction absorbed and in the renal elimination rate. In healthy volunteers, areas under plasma concentration-time curves varied up to twofold on repeated testing with oral doses, ${ }^{5}$ and similar variations were observed in two patients of this series who were studied twice or three times. When the AUC values were adjusted to a $60 \mathrm{mg}$ dose in the patient group, their mean was similar to that observed in healthy subjects, ${ }^{5}$ but interindividual variability was considerably higher.

Differences in mean plasma concentration/ dose ratios between patients receiving and not receiving glucocorticoid comedication could not be detected, a finding that conflicts with the observation that addition of prednisolone considerably reduced pyridostigmine availability.

Clear cut pyridostigmine plasma concentration effect relationships were not established in any investigations including the present one, particularly when studies were carried out under conditions of routine treatment. In two out of four and two out of nine outpatients, significant associations were detected between plasma concentrations and electromyographic findings ${ }^{14}$ or muscle strength, ${ }^{1}$ respectively. Since this study comprised a larger and unselected patient group, the results appear to be comparable. Maximum measured concentrations in patients with significant correlations were between 48 and $85 \mathrm{ng} / \mathrm{ml}$ in the present series and between 10 and $77 \mathrm{ng} / \mathrm{ml}$ in the previous ones; $;^{14}$ the latter values have to be regarded as lower limits, because in the two investigations unbuffered plasma samples were stored at $-20^{\circ} \mathrm{C}$ for unspecified lengths of time, so that pyridostigmine may have been partially hydrolysed. ${ }^{5}$

More consistent results were obtained on pyridostigmine administration to patients with myasthenia from whom medication had been withheld, so that drug plasma concentrations had declined to undetectable levels. In three patients given pyridostigmine iv, functional improvement occurred up to $30-60 \mathrm{ng} / \mathrm{ml}$ and functional impairment at higher levels. ${ }^{12}$ Ingestion of $60-120 \mathrm{mg}$ pyridostigmine by 10 patients resulted in high correlation coefficients between plasma concentrations and parameters of muscular function in some patients, but none of these achieved significance at the $p<0.05$ level. ${ }^{7}$ Peak levels were below $90 \mathrm{ng} / \mathrm{ml}$ in all but one patient, and inspection of data from the latter discloses functional deterioration at levels of 100 and $125 \mathrm{ng} / \mathrm{ml}$.

Definition of a therapeutically favourable plasma concentration range has to be done with caution, also because various measures of neuromuscular function often do not show parallel changes. ${ }^{7}$ Levels below $50 \mathrm{ng} / \mathrm{ml}$ are not necessarily suboptimal, because a lack of significant correlations with functional data in most of the patients in this concentration range may be due to the small fluctuations during the investigation. In several of these cases, clinico- physiological data showed some change which demonstrates that functional measures are influenced by factors in addition to drug level. In a few cases clinical improvements have been observed on raising very low or undetectable concentrations into the range $25-50 \mathrm{ng} / \mathrm{ml},{ }^{714}$ while little response was associated with still lower concentrations..$^{715}$ The fact that in this study significant correlations were confined to cases with peak plasma concentrations between 48 and $85 \mathrm{ng} / \mathrm{ml}$ and that close-to-significant correlations occurred in an investigation with the same values, ${ }^{7}$ would argue in favour of an optimal range around $50-100 \mathrm{ng} / \mathrm{ml}$. On the other hand, pyridostigmine doses far exceeding those administered now and correspondingly high plasma concentrations were reported in some publications, ${ }^{2412}$ particularly in patients with severe and poorly controlled disease. ${ }^{24}$ Were these patients overmedicated? According to extensive clinical experience gained by one of us (FS), therapeutic results achievable with oral pyridostigmine doses in excess of $400 \mathrm{mg} /$ day are not better than those with intermediate or low doses.

Our data gives additional reasons to warn against high plasma concentrations, because the patient exhibiting the highest levels (peak $197 \mathrm{ng} / \mathrm{ml}$, mean $117 \mathrm{ng} / \mathrm{ml}$ ) showed not only cholinergic overstimulation, but also poor neuromuscular function. Moreover, two patients investigated repeatedly exhibited more impairment during periods with maximal concentrations above $100 \mathrm{ng} / \mathrm{ml}$. It could be argued that patients with more severe disease required higher doses and therefore attained higher plasma levels, but this can be refuted, because doses did not differ among patient groups defined by mean or maximal plasma concentrations.

The authors thank Professor K Dietz, Department of Biomedical Statistics, University of Tübingen, for valuable advice concerning the statistical evaluation. They are grateful to Professor J Dichgans for his interest in and support of the investigations and to Mrs B Wagner for skillful technical assistance. The study has been supported by grants from the Deutsche Forschungsgemeinschaft (Schu 508/2-1 and $\mathrm{Br}$ $478 / 9-2)$

1 Davison SC, Hyman NM, Dehghan A, Chan K. The relationship of plasma levels of pyridostigmine to clinical effect in patients with myasthenia gravis. $J$ Neurol Neurosurg Psychiatry 1981;44:1141-5.

2 White MC, DeSilva P, Havard CWH. Plasma pyridostigmine levels in myasthenia gravis. Neurology (Ny) 1981;31:145-50.

3 Havard CWH, Scadding GK. Myasthenia gravis: pathogenesis and current concepts of management. Drugs 1983;26:174-84.

4 Aquilonius S-M, Eckernäs S-A, Hartvig P, Lindström B, Osterman PO. Pharmacokinetics and oral bioavailability of pyridostigmine in man. Eur $J$ Clin Pharmacol 1980;18:423-8

5 Breyer-Pfaff U, Maier U, Brinkmann AM, Schumm F. Pyridostigmine kinetics in healthy subjects and patients with myasthenia gravis. Clin Pharmacol Ther 1985;37:495-501.

6 Aquilonius S-M, Hartvig P. Clinical pharmacokinetics of cholinesterase inhibitors. Clin Pharmacokin 1986;11: 236-49.

7 Milner-Brown HS, Mellenthine M, Sharma ML, Miller RG. Quantitative correlation between plasma pyridostigmine levels and neuromuscular function in myasthenia gravis. Neurology 1987;37:800-3.

8 Osserman KE. Myasthenia gravis. London: Grune and Stratton 1958.

9 Schumm F, Stöhr M. Accessory nerve stimulation in the assessment of myasthenia gravis. Muscle Nerve

10 Besinger UA, Toyka KV, Heininger K, Fateh-Moghadam A, Schumm F, Sandel P, Birnberger KL. Long-term correlation of clinical course and acetylcholine receptor 
antibody in patients with myasthenia gravis. Ann $N Y$ Acad Sci 1981;377:812-5.

11 Calvey TN, Chan K. Plasma pyridostigmine levels in patients with myasthenia gravis. Clin Pharmacol Ther 977;21:187-93.

12 Aquilonius S-M, Eckernäs S-A, Hartvig P, Lindström B pyridostigmine and neostigmine in patients with myasthenia gravis. J Neurol Neurosurg Psychiatry 1983; 46:929-35.
13 Schumm F, Gaertner HJ, Wiatr G, Dichgans J Serumspiegel von Pyridostigmin bei Myasthenia gravis: Methoden und klinische Bedeutung. Fortschr Neurol Psychiatrie 1985;53:201-11.

14 Chan K, Calvey TN. Plasma concentration of pyridostigmine and effects in myasthenia gravis. Clin Pharmacol Ther 1977;22:596-601.

15 Cohan SL, Dretchen KL, Neal A. Malabsorption of pyridostigmine in patients with myasthenia gravis. pyridostigmine in patients with myast
Neurology (Minneap) 1977;27:299-301. 